\title{
Non-Pharmacological Interventions for Chronic Pain and Depression: any Possible Applications of Multisensory Feedback Approaches Based on Body Representation?
}

\author{
Matteo Martini* \\ School of Psychology, University of East London, UK
}

Submission: March 28, 2017; Published: March 31, 2017

*Corresponding author: Matteo Martini, School of Psychology, University of East London, Water Lane, London E15 4LZ, UK, Email: M.Martini@uel.ac.uk

\begin{abstract}
Chronic pain is often associated with sleep disruption, fatigue, cognitive deficits and mood alterations. In particular a bidirectional relationship exists between pain and mood disorders, for example chronic pain and depression. When these morbidities co-occur, the patient's quality of life can significantly decrease. Different pharmacological solutions have been proposed to target both symptom atologies but misuse, addiction and side effects may limit their adoption. Non-pharmacological interventions like psychotherapy and physical activity have been shown to yield promising results in the management of both chronic pain and mood disorders. In the last twenty years multisensory feedback approaches based on body representation have also been shown to be a valid method to treat different forms of chronic pain. However, comorbid mood disorders have not been taken in consideration by this latter approach. The advances in the treatment of chronic pain with comorbid depression may benefit from future studies using multisensory feedback approaches based on body representation.

Keywords: Chronic pain; Depression; Cognitive behavioural therapy; Physical activity; Exercise; Body representation; Body ownership; Disability

Abbreviations: PFC: Prefrontal Cortex; SNRIs: Serotonin-Norepinephrine Reuptake Inhibitors; CBT: Cognitive Behavioural Therapy; RCT: Randomized Controlled Trials; iCBT: internet-delivered Cognitive Behavioural Therapy; MBSR: Mindfulness-Based Stress Reduction; ACT: Acceptance and Commitment Therapy; BDNF: Brain-Derived Neurotrophic Factor; CRPS: Complex Regional Pain Syndrome; BID: Body Image Dissatisfaction; BPQ: Body Perception Questionnaire
\end{abstract}

\section{Introduction}

Chronic pain is a clinical condition that can severely affect the patient's quality of life, and it represents a major socio-sanitary concern, especially for an increasing ageing population. Indeed, it is estimated that about $20 \%$ of the European population [1] and $30 \%$ of the US population is afflicted by it [2] and its prevalence increases with age [3]. Traditional pharmaceutical interventions such as opioids and non-steroidal anti-inflammatory drugs (NSAIDs), may lead to iatrogenic outcomes, substance abuse and side effects [4]. The recent decease of two notorious pop stars like Michael J. Jackson and Prince Rogers Nelson, is just one prominent example of the powerful adverse potential of painkillers.
A gloomier picture is depicted when considering that chronic pain is commonly associated with mood disorders such as anxiety and depression [5]. Indeed, pain and depression share common neurological alterations such as increased limbic area activation, atrophy of the hippocampus and a decreased prefrontal cortex (PFC) activity [6], and it has been deemed that they can co-occur in up to $80 \%$ of patients [7]. When this comorbidity is present, the pharmacological aid is usually represented by tricyclic antidepressants, anticonvulsants, or serotonin-norepinephrine reuptake inhibitors (SNRIs), which have been shown to be effective both for chronic pain and mood disorders, especially depression [8]. However, extra pyramidal 
symptoms, cardiac and sexual dysfunctions are only few of the possible side effects reported following the use of these drugs $[9,10]$.

\section{Discussion}

Non-pharmacological treatments have been adopted in an attempt to bypass the side effects, abuse and addiction related to drug use. Although mixing results have been reported, the majority of the studies focussing on alternative interventions provide encouraging findings for the treatment of both pain and depression. These studies also hint at the importance of tailor-made interventions whenever necessary and, arguably, at multidisciplinary approaches to maximize the efficacy of the overall treatment.

\section{Psychotherapy}

Psychotherapy, for example, has been successfully used for the management of both conditions. In particular cognitive behavioural therapy (CBT), which targets maladaptive thinking through cognitive restructuring techniques, integrating it with behavioural strategies to modify dysfunctional conduct, has been shown to be efficacious in the treatment of chronic pain [11], depression [12] and both syndromes together [13]. For instance, Tan and co-workers showed that an intensive 6 to 9-day group CBT programme can bring about beneficial outcomes decreasing levels of pain, pain distress, depression, anxiety and stress in a group of chronic pain patients that last at least for 6 months [14]. Similarly, Wong and colleagues found that pain self-efficacy as well as depression levels and quality of life, significantly improved after a 8-week programme of CBT for patients with intractable chronic pain conditions [15]. In recent years, CBT trials took advantage of technological resources for the delivery of the therapeutical sessions. In randomized controlled trials (RCT) using internet-delivered CBT (iCBT) for chronic pain patients with comorbid mood syndromes, treatment-group participants reported significantly greater improvements than controlgroup participants in levels of depression, anxiety, average pain levels and pain catastrophizing [16,17]. Nevertheless, CBT is not the only psychological intervention that has been used on these type of patients. Valid alternatives have been proposed, such as mindfulness-based stress reduction (MBSR) programs and acceptance and commitment therapy (ACT), however their efficacy do not seem to exceed the efficacy of CBT [13].

\section{Physical Activity}

Physical activity represents another compelling nonpharmacological approach that has been shown to yield promising results. Its beneficial effects on pain and mood have been reported both in animal $[18,19]$ and human models [20-22]. Ekici and co-workers showed how physical exercise (pilates) significantly reduced pain and depression levels in a group of women with fibromyalgia, after a 4-week programme [23]. On a similar sample of patients, Valim and collaborators showed how aerobic exercise was more effective than stretching in reducing pain and in improving functionality and mood, including depression, after a period of 20 weeks [24]. In another RCT, Tekur and colleagues showed how a 7-day intensive Yoga programme can reduce pain, anxiety and depression in a group of chronic low back pain patients, more successfully than physiotherapy exercises [25]. Lim et al. found improvements in joint mobility, functional capacity, pain and depression following a daily 20-min exercise programme developed over8 weeks in a group of patients with arthritis as compared to a control group [26].

A down-regulation of the brain-derived neurotrophic factor (BDNF) and of the serotonergic pathway, among other neuroendocrine alterations, has been shown to be common in depression, sleep disturbances and chronic pain [6]. BDNF and serotonin (5-HT) levels have been shown to be mutually influencing [27] and physical exercise, either acute or regular, is known to increase levels of BDNF [28,29] and 5-HT [30]. Thus, interventions based on physical activity could be particularly efficacious in the treatment of chronic pain and depression restoring higher levels of BDNF and 5-HT. Yet, it is likely that the reasons underlying the efficacy of treatments based on physical activity are multi factorial: exercise promotes increasing levels of neurotransmitters and neuropeptides that are essential for mood regulation, it reduces cortisol, distract from negative thoughts and advocate a better functionality and a general sense of well-being [31,32].

\section{Multisensory Feedback and Body Representation}

Over the last 20 years multisensory feedback approaches, especially those based on the vision of the body, have been increasingly adopted in the treatment of both chronic [33] and acute pain states [34]. In healthy participants, the vision of one's own body has been shown to have analgesic properties during acute pain states [35], and such effect has been shown to hold true even during the vision of prosthetic [36] or virtual limbs [37], provided that an illusion of body ownership over the external limb is established [38]. The most meaningful results deriving from approaches based on multisensory feedback however, have been obtained with chronic pain patients. In the seminal study conducted by Ramachandran and RogersRamachandran, the authors showed the scientific community how it was possible to alleviate chronic phantom limb pain, a condition up to then regarded as intractable, by means of a simple mirror [39]. So, in the so-called 'mirror therapy' a mirror is placed vertically on a table and reflects the patients' healthy upper limb, providing the illusory visual feedback that the missing limb is back in place and is able to move [39]. A study using mirror therapy has shown how this type of visual feedback is effective in reducing pain and enhance motor functionality in the affected limb of stroke patients with complex regional pain syndrome (CRPS) type 1 [40]. A recent review has reported how both graded motor imagery and mirror therapy can improve pain in CPRS type 1 patients, although the authors pointed out that results are not conclusive [41]. 
Not only the vision of the 'normal' healthy own limb has been shown to be useful with chronic pain patients. In fact, also the use of visual distortions of the body has been shown to be particularly promising for certain kind of chronic pain patients. For example, using binoculars Moseley and collaborators made their chronic hand pain patients look at magnified or minified views of their own limb. Pain was found to increase during the vision of the magnified, moving limb, while it was decreased in the minified visual condition [42]. Yet, it is important to note that the same visual distortion might not work for everybody. Preston and Newport made use of a real-time capture system to manipulate the shape of the hands of osteoarthritis patients. The authors found out that stretching or shrinking the painful hand brought about pain relief in the majority of patients, although some individuals benefitted from the vision of the shrunk hand, while others from the vision of the stretched one or even from both visual conditions [43]. In a revised version of the mirror therapy, based on non-immersive virtual reality system, Sato et al. found that 4 out of 5 CPRS patients experienced pain relief following the virtual mirror therapy, and 2 of these ended their visit to the pain clinic after 5 sessions [44]. Using 3D augmentedreality on a group of neuropathic pain patients, Mouraux and colleagues exposed their patients to 5 sessions of a modified version of the mirror therapy. Sessions lasted 20 minutes and were spread over 1 week. What the authors witnessed was an increasing reduction of pain as well as an increase in duration of pain relief in their patients after each session [45].

In general, approaches based on sensory feedback, like those focussing on the vision of the body, seem to be particularly effective in those chronic pain conditions where a distorted representation of the body is present, such as in CRPS [46,47], back pain [48], osteoarthritis [49] and fibromyalgia [50]. After all, there seem to be a strong link between the magnitude of persistent pain states, the degree in body image alteration and extent of changes in the cortical representation of the body [51,52]. While some authors believe it is unlikely that the distortion in body image or the cortical reorganization can cause pain, but rather pain may influence them [51], others support the view that, at least in some patients, pain can be a consequence and not the cause of an altered body representation [53]. As body representations are mainly resulting from the integration of sensory information, and chronic pain conditions are characterized by disturbances in the proprioceptive, exteroceptive and interoceptive systems [54], a distorted body image in chronic pain patients is likely the result of an alteration of the sensory systems, which relates to a cortical (maladaptive) reorganization of the sensory-motor maps [52]. On the same line, recently it has been suggested that the vision of the body generates analgesia by increasing intracortical inhibition in the primary somatosensory cortex (SI), which in turn could lead to an increased organization of the somatosensory maps within this area, shrinking the size of their receptive fields (called "somatosensory sharpening") [55].
Can there be an application of multisensory feedback approaches based on the vision of the body in patients with comorbid depression? It is known that depression is associated to high levels of body image dissatisfaction (BID) [56-58]. Furthermore, it has been shown how pain, BID and depression can be interconnected: higher levels of pain lead to higher BID states which in turn lead to greater depressive symptoms in a group of patients with lymphedema [59]. However, BID refers to the emotional, and not to the perceptional (for ex. shape, size) component of the body image, targeted by multisensory feedback approaches. Still, depression can also be associated with the physical representation of one's body. So, similarly to chronic pain patients, patients with major depression can be affected by an altered body image in its sensorial/physical aspects. For instance, Wiebking and collaborators investigated the behavioural and the neural correlates of interoception in depressed subjects and healthy controls using the Body Perception Questionnaire (BPQ) and a heartbeat perception task in fMRI [60]. Patients showed significantly higher scores in the BPQ and reduced anterior insular activity during the resting periods of the heartbeat perception task. Importantly, BPQ scores correlated with depression severity. Thus, patients with major depression reported behavioural, neural and somato-vegetative abnormalities related to their interoceptive awareness [60], which is one of the key factors for shaping one's own body representation [54].

Anyway, more studied are needed to assess whether the perceptional aspect of body image are altered in patients with depression. Given the strong bidirectional relationship between chronic pain and depressive symptoms, and taking into account the beneficial effects on pain of multisensory feedback approaches based on the vision of the body, it could be important to measure the impact of this type of intervention on depression levels, besides pain. However, to the author's knowledge, there are no studies, so far, taking into account the effects of such approach on pain and mood disorders. Future studies filling up this hole in the scientific literature are welcome.

\section{Conclusion}

The relationship between chronic pain and depression is bidirectional, so that chronic pain can trigger depression and vice versa. These two conditions are strictly intertwined, sharing common predictors [61], and partly relying on the same neural mechanism [8]. They are so interrelated that whichever of the two kicks in first, there is a high probability that the other one will follow in two years' time [61]. Furthermore, these two conditions implies wide-spread and profound neurobiological complex alterations [5]. Given the emotional and economic burden that chronic pain and depression can represent for the patient, a diverse range of treatments is currently available. However, despite the great attention given to explain why depression and anxiety often co-occur during chronic pain, there is a paucity of investigations that target these morbidities 
collectively. Multisensory feedback interventions, especially those relying on illusory body perception, have been shown to be an effective non-pharmacological solution to treat different forms of chronic pain. Unfortunately, depression seems to have been completely neglected by this approach so far. It is therefore advisable that future studies making use of multisensory feedback take in consideration the assessment of both chronic pain levels and mental health variables. This will allow a more extensive comparison between treatments, therefore fostering the creation of better multidisciplinary interventions.

\section{Acknowledgment}

The author is grateful to Natalia Arias-del Castillo for her invaluable support.

\section{References}

1. Breivik H, Collett B, Ventafridda V, Cohen R, Gallacher D (2006) Survey of chronic pain in Europe: Prevalence, impact on daily life, and treatment. Eur J Pain 10(4): 287-287.

2. Johannes CB, Le TK, Zhou X, Johnston JA, Dworkin RH (2010) The Prevalence of Chronic Pain in United States Adults: Results of an Internet-Based Survey. J Pain 11(11): 1230-1239.

3. Savvas SM, Gibson SJ (2016) Overview of Pain Management in Older Adults. Clin Geriatr Med 32(4): 635-650.

4. Carter GT, Duong V, Ho S, Ngo KC, Greer CL, Weeks DL (2014) Side effects of commonly prescribed analgesic medications. Phys Med Rehabil Clin N Am 25(2): 457-70.

5. Yalcin I, Barrot M (2014) The anxiodepressive comorbidity in chronic pain. Curr Opin Anaesthesiol 27(5): 520-527.

6. Boakye PA, Olechowski C, Rashiq S, Verrier MJ, Kerr B, et al. (2016) A Critical Review of Neurobiological Factors Involved in the Interactions Between Chronic Pain, Depression, and Sleep Disruption. Clin J Pain 32(4): 327-336.

7. Poole H, White S, Blake C, Murphy P, Bramwell R (2009) Depression in chronic pain patients: prevalence and measurement. Pain Pract 9(3): 173-180.

8. Hooten WM (2016) Chronic Pain and Mental Health Disorders: Shared Neural Mechanisms, Epidemiology, and Treatment. Mayo Clin Pro 91(7): 955-970.

9. Govoni S, Racchi M, Masoero E, Zamboni M, Ferini-Strambi L (2001) Extrapyramidal symptoms and antidepressant drugs: neuropharmacological aspects of a frequent interaction in the elderly. Mol Psychiatry 6(2): 134-142.

10. David DJ, Gourion D (2016) Antidepressant and tolerance: Determinants and management of major side effects. Encephale 42(6): 553-561.

11. Ehde DM, Dillworth TM, Turner JA (2014) Cognitive-behavioral therapy for individuals with chronic pain: Efficacy, innovations, and directions for research. Am Psychol 69(2): 153-166.

12. Furukawa TA, Weitz ES, Tanaka S, Hollon SD, Hofmann SG, et al. (2017) Initial severity of depression and efficacy of cognitive-behavioural therapy: individual-participant data meta-analysis of pill-placebocontrolled trials. Br J Psychiatry 210(3): 190-196.

13. Veehof MM, Oskam M-J, Schreurs KMG, Bohlmeijer ET (2011) Acceptance-based interventions for the treatment of chronic pain: A systematic review and meta-analysis. Pain 152(3): 533-542.

14. Tan EP, Tan ES, Ng BY (2009) Efficacy of cognitive behavioural therapy for patients with chronic pain in Singapore. Ann Acad Med Singapore 38(11): 952-959.

15. Wong M, Rietzschel J, Mulherin D, David C (2009) Evaluation of a multidisciplinary outpatient pain management programme based at a community hospital. Musculoskeletal Care 7(2): 106-120.

16. Dear BF, Titov N, Perry KN, Johnston L, Wootton BM, et al. (2013) The Pain Course: a randomised controlled trial of a clinician-guided Internet-delivered cognitive behaviour therapy program for managing chronic pain and emotional well-being. Pain 154(6): 942-950.

17. Buhrman M, Syk M, Burvall O, Hartig T, Gordh T, et al. (2015) Individualized Guided Internet-delivered Cognitive-Behavior Therapy for Chronic Pain Patients With Comorbid Depression and Anxiety. Clin J Pain 31(6): 504-516.

18. Leung A, Gregory NS, Allen LA, Sluka KA (2016) Regular physical activity prevents chronic pain by altering resident muscle macrophage phenotype and increasing interleukin-10 in mice. Pain 157(1): 70-79.

19. Nishijima T, Llorens-Martín M, Tejeda GS, Inoue K, Yamamura Y, et al. (2013) Cessation of voluntary wheel running increases anxiety-like behavior and impairs adult hippocampal neurogenesis in mice. Behav Brain Res 245: 34-41.

20. Kelley GA, Kelley KS, Hootman JM, Jones DL (2011) Effects of community-deliverable exercise on pain and physical function in adults with arthritis and other rheumatic diseases: A meta-analysis. Arthritis Care Res (Hoboken) 63(1): 79-93.

21. Kaleth AS, Saha CK, Jensen MP, Slaven JE, Ang DC (2013) Effect of moderate to vigorous physical activity on long-term clinical outcomes and pain severity in fibromyalgia. Arthritis Care Res (Hoboken) 65(8): 1211-1218.

22. Peluso MAM, Guerra de Andrade LHS (2005) Physical activity and mental health: the association between exercise and mood. Clinics (Sao Paulo) 60(1): 61-70.

23. Ekici G, Akbayrak T, Yakut E (2008) Effects of Pilates exercises and connective tissue manipulation on pain and depression in females with fibromyalgia: a randomized controlled trial. Fiz Reha bilitasyon 19(2): 47-54.

24. Valim V, Oliveira L, Suda A, Silva L, de Assis M, et al. (2003) Aerobic fitness effects in fibromyalgia. J Rheumatol 30(5): 1060-1069.

25. Tekur P, Nagarathna R, Chametcha S, Hankey A, Nagendra HR (2012) A comprehensive yoga programs improves pain, anxiety and depression in chronic low back pain patients more than exercise: An RCT. Complement Ther Med 20(3): 107-118.

26. Lim HJ, Moon YI, Lee MS (2005) Effects of home-based daily exercise therapy on joint mobility, daily activity, pain, and depression in patients with ankylosing spondylitis. Rheumatol Int 25(3): 225-229.

27. Martinowich K, Lu B (2008) Interaction between BDNF and Serotonin: Role in Mood Disorders. Neuropsychopharmacology 33(1): 73-83.

28. Huang T, Larsen KT, Ried-Larsen M, Møller NC, Andersen LB (2014) The effects of physical activity and exercise on brain-derived neurotrophic factor in healthy humans: A review. Scand J Med Sci Sports 24(1): 1-10.

29. Coelho FG, Gobbi S, Andreatto CA, Corazza DI, Pedroso RV, et al. (2013) Physical exercise modulates peripheral levels of brain-derived neurotrophic factor (BDNF): A systematic review of experimental studies in the elderly. Arch Gerontol Geriatr 56(1): 10-15.

30. Melancon MO, Lorrain D, Dionne IJ (2014) Changes in markers of brain serotonin activity in response to chronic exercise in senior men. Appl Physiol Nutr Metab 39(11): 1250-1256.

31. Surah A, Baranidharan G, Morley S (2014) Chronic pain and depression. Contin Educ Anaesthesia, Crit Care Pain. Oxford University Press 14(2): 85-89. 
32. Stagg NJ, Mata HP, Ibrahim MM, Henriksen EJ, Porreca F, et al. (2011) Regular exercise reverses sensory hypersensitivity in a rat neuropathic pain model: role of endogenous opioids. Anesthesiology 114(4): 940948.

33. Senkowski D, Heinz A (2016) Chronic pain and distorted body image: Implications for multisensory feedback interventions. Neurosci Biobehav Rev 69: 252-259.

34. Martini M (2016) Real, rubber or virtual: The vision of \&quot;one's own\&quot; body as a means for pain modulation. A narrative review. Conscious Cogn 43: 143-151.

35. Longo MR, Betti V, Aglioti SM, Haggard P (2009) Visually induced analgesia: seeing the body reduces pain. J Neurosci Off J Soc Neurosci 29(39): 12125-12130.

36. Hegedüs G, Darnai G, Szolcsányi T, Feldmann A, Janszky J, et al. (2014) The rubber hand illusion increases heat pain threshold. Eur J Pain 18(8): 1173-1181.

37. Martini M, Perez-Marcos D, Sanchez-Vives MV (2014) Modulation of pain threshold by virtual body ownership. Eur J Pain 18(7): 10401048.

38. Martini M, Perez-Marcos D, Sanchez-Vives MV (2015) Author's reply to the commentary by Gilpin et al. Eur J Pain 19(1): 143-144.

39. Ramachandran VS, Rogers-Ramachandran D (1996) Synaesthesia in Phantom Limbs Induced with Mirrors. Proc R Soc B Biol Sci 263: 377 386

40. Cacchio A, De Blasis E, Necozione S, Orio F di, Santilli V (2009) Mirror Therapy for Chronic Complex Regional Pain Syndrome Type 1 and Stroke. N Engl J Med 361: 634-636.

41. Méndez-Rebolledo G, Gatica-Rojas V, Torres-Cueco R, AlbornozVerdugo M, Guzmán-Muñoz E (2016) Update on the effects of graded motor imagery and mirror therapy on complex regional pain syndrome type 1: A systematic review. J Back Musculoskelet Rehabil 1-9.

42. Moseley GL, Parsons TJ, Spence C (2008) Visual distortion of a limb modulates the pain and swelling evoked by movement. Curr Biol CB 18(22): R1047-1048.

43. Preston C, Newport R (2011) Analgesic effects of multisensory illusions in osteoarthritis. Rheumatology (Oxford) 50(12): 2314-2315.

44. Sato K, Fukumori S, Matsusaki T, Maruo T, Ishikawa S, et al. (2010) Nonimmersive virtual reality mirror visual feedback therapy and its application for the treatment of complex regional pain syndrome: an open-label pilot study. Pain Med 11(4): 622-629.

45. Mouraux D, Brassinne E, Sobczak S, Nonclercq A, Warzée N, et al. (2016) 3D augmented reality mirror visual feedback therapy applied to the treatment of persistent, unilateral upper extremity neuropathic pain: a preliminary study. J Man Manip Ther 1-7.

46. Moseley GL (2005) Distorted body image in complex regional pain syndrome. Neurology 65(5): 773-773.
47. Reinersmann A, Landwehrt J, Krumova EK, Ocklenburg S, Güntürkün O et al. (2012) Impaired spatial body representation in complex regional pain syndrome type 1 (CRPS I). Pain 153(11): 2174-2181.

48. Moseley LG (2008) I can't find it! Distorted body image and tactile dysfunction in patients with chronic back pain. Pain 140(1): 239-243.

49. Gilpin HR, Moseley GL, Stanton TR, Newport R (2015) Evidence for distorted mental representation of the hand in osteoarthritis. Rheumatology (Oxford) 54(4): 678-682.

50. Akkaya N, Akkaya S, Atalay NS, Balci CS, Sahin F (2012) Relationship between the body image and level of pain, functional status, severity of depression, and quality of life in patients with fibromyalgia syndrome. Clin Rheumatol 31(6): 983-988.

51. Lotze M, Moseley GL (2007) Role of distorted body image in pain. Curr Rheumatol Rep 9(6): 488-496.

52. Moseley GL, Flor H (2012) Targeting Cortical Representations in the Treatment of Chronic Pain. Neurorehabil Neural Repair 26(6): 646652.

53. Bultitude JH, Rafal RD (2010) Derangement of body representation in complex regional pain syndrome: report of a case treated with mirror and prisms. Exp Brain Res 204(3): 409-418.

54. Tsay A, Allen TJ, Proske U, Giummarra MJ (2015) Sensing the body in chronic pain: a review of psychophysical studies implicating altered body representation. Neurosci Biobehav Rev 52: 221-232.

55. Haggard P, Iannetti GD, Longo MR (2013) Spatial sensory organization and body representation in pain perception. Curr Biol 23(4): R164176.

56. Kostanski M, Gullone E (1998) Adolescent body image dissatisfaction: relationships with self-esteem, anxiety, and depression controlling for body mass. J Child Psychol Psychiatry 39(2): 255-262.

57. Stevens SD, Herbozo S, Morrell HE, Schaefer LM, Thompson JK (2016) Adult and childhood weight influence body image and depression through weight stigmatization. J Health Psychol.

58. Rosenström T, Jokela M, Hintsanen M, Josefsson K, Juonala M, et al. (2013) Body-image dissatisfaction is strongly associated with chronic dysphoria. J Affect Disord 150(2): 253-260.

59. Teo I, Novy DM, Chang DW, Cox MG, Fingeret MC (2015) Examining pain, body image, and depressive symptoms in patients with lymphedema secondary to breast cancer. Psychooncology 24(11): 1377-1383.

60. Wiebking C, Bauer A, de GRECK M, Duncan NW, Tempelmann C, et al. (2010) Abnormal body perception and neural activity in the insula in depression: An fMRI study of the depressed "material me." World J Biol Psychiatry 11(3): 538-549.

61. Chou KL (2007) Reciprocal relationship between pain and depression in older adults: Evidence from the English Longitudinal Study of Ageing. J Affect Disord 102(1-3): 115-123. 
This work is licensed under Creative Commons Attribution 4.0 License

DOI: $10.19080 /$ PBSIJ.2017.02.555599

\section{Your next submission with JuniperPublishers will reach you the below assets}

- Quality Editorial service

- Swift Peer Review

- Reprints availability

- E-prints Service

- Manuscript Podcast for convenient understanding

- Global attainment for your research

- Manuscript accessibility in different formats ( Pdf, E-pub, Full Text, Audio)

- Unceasing customer service

Track the below URL for one-step submission https://juniperpublishers.com/online-submission.php 